\title{
Simple Face Shield for Public as a Crucial Factor to Slow Aerosol Transmission During Unlock Phase of COVID Pandemic
}

\author{
Mubarak Muhamed Khan ${ }^{1}$ - Sapna Ramkrishna $\operatorname{Parab}^{1}$ (D)
}

Received: 17 July 2020/ Accepted: 18 August 2020/Published online: 27 August 2020

(C) Association of Otolaryngologists of India 2020

\begin{abstract}
Coronavirus disease 2019 (COVID-19) is an infectious disease caused by severe acute respiratory syndrome coronavirus 2 (SARS-CoV-2). Till now, the total number of affected patients are 9,073,969 with 471,199 deaths and 3,747,128 currently infected active cases. Major concern is due to the droplets and aerosols of SARS CoV 2 causing the rapid spread and transmission. Since last 3 months we are using the indigenous face shields for our health care workers which costs only 0.13 USD per shield. Now we propose the use of this same shield for the general public to reduce the transmission of SARS CoV2.
\end{abstract}

Keywords COVID $19 \cdot$ Pandemic

Face masks: face shield - Public use - Global health .

Public health

\section{Introduction}

The world is witnessing a terrible health menace during COVID 19 pandemic since its outbreak. Till now, the total number of affected patients are 9,073,969 with 471,199 deaths and 3,747,128 currently infected active cases [1]. Major concern is due to the droplets and aerosols of SARS $\mathrm{CoV} 2$ causing the rapid spread and transmission.

Electronic supplementary material The online version of this article (https://doi.org/10.1007/s12070-020-02078-3) contains supplementary material, which is available to authorized users.

Sapna Ramkrishna Parab drsapnaparab@gmail.com

1 Sushrut ENT Hospital and Dr. Khan's ENT Research Center, Talegaon Dabhade, India
The measures taken during lockdown has helped to curb the spread of COVID 19, but the risk of increase in cases and possible resurgence is expected during the unlock. During the easing of strict lockdown, the shopping malls, restaurants, religious places, theatres, cinemas, casinos, bars, restaurants, hotels, schools will gradually reopen to its full form sooner or later not only in India but all over the world. India and other Asian countries with large dense populations, the unlock period will have many problems to be solved. The Indian population is $1,352,642,280$ with the population density [2] of 464 per $\mathrm{km}^{2}$.

In addition there are other issues in India like the large amount of labour migration in crowded trains and public transports, and the fact that many daily wage workers have no choice but to go to work every day inspite of the corona crises. In many urban areas, it's impossible to maintain social distancing. In such situations, where lakhs of people are on the streets at a time for travel, work, religious gatherings and other essential work, it seems impossible to save ourselves from the droplets and aerosols generated unless precautions are taken by each and every one. In a highly populated country like India, people seeking medical advice in public and private hospitals are enormous. In such a scenario, recommending a mandatory use of a simple cloth mask (single or double layered) is a good option for all for preventing the aerosols created by speech to a certain extent. Adding face shields as protective measure for the general public may give extra safety. Several studies have shown that people expel aerosol particles containing potentially infectious microorganisms during coughing, speaking, or breathing for distances greater than two metres [3, 4]. Small droplets (less than $\sim 10 \mu \mathrm{m}$ ) are much less prone to impaction or settling; they can remain airborne for an extended time and be spread throughout a room by air currents, especially after 
drying [5]. Published data have suggested that sneezing may produce as many as 40000 droplets between 0.5 and $12 \mu \mathrm{m}$ in diameter that may be expelled at speeds up to $100 \mathrm{~m} / \mathrm{s}$, whereas coughing may produce up to 3000 droplet nuclei, about the same number as talking for 5 min [6].

Since last 3 months we are using the indigenous face shields [7-9] for our health care workers which costs only 0.13 USD per shield. Now we propose the use of this same shield for the public to prevent the transmission of SARS CoV2. The additional burden of testing each and every person is a mammoth task and such asymptomatic carriers pose a grave risk for spread. With the normalising of life during gradual unlock, the risk of spread of the virus by aerosol and droplets will increase and it is of utmost importance to check the spread of the coronavirus.

The method of preparation of indigenous face shield [7-9]: (video 1)

a. A4 size OHP sheet of 150 to 200 micron thickness is taken

b. 8 holes are made across length of OHP sheet with office punching machine. The ribbon is passed alternately through created holes for tying around head.

For re-usability simple safety any of the measures may be adopted:

1. The removed face shields must be kept in $1 \%$ Sodium Hypochlorite solution for $10 \mathrm{~min}$.

2. Washing the face shields with soap and water and drying in sunlight

We recommend its usage by general public in crowded places,during transportation in crowded trains and buses, in schools by teachers, in hotels by chef, waiters and the staff,by street vendors, and by all patients who are visiting OPD of any speciality.

\section{Conclusion}

Combining economical mask with a face shield in densely populated countries could become a crucial factor in slowing the COVID 19 spread.
Funding This study was not financially supported from external sources.

\section{Compliance with ethical standards}

Conflict of interest The authors declare that they have no conflict of interest.

\section{References}

1. https://www.worldometers.info/coronavirus/

2. https://www.worldometers.info/world-population/india-population/

3. Fabian P, McDevitt JJ, DeHaan WH, Fung RO, Cowling BJ, Chan $\mathrm{KH}$, Leung GM, Milton DK (2008) Influenza virus in human exhaled breath: an observational study. PLoS One 3(7):e2691

4. Lindsley WG, Reynolds JS, Szalajda JV, Noti JD, Beezhold DH (2013) A cough aerosol simulator for the study of disease transmission by human cough-generated aerosols. Aerosol Sci Technol 47(8):937-944. https://doi.org/10.1080/02786826.2013. 803019

5. CDC (2006) Interim guidance on planning for the use of surgical masks and respirators in health care settings during an influenza pandemic. http://home.nyc.gov/html/doh/downloads/pdf/bhpp/ bhpp-interrim-maskguide120106.pdf. Accessed 18 March 2013

6. Tang JW et al (2006) Factors involved in the aerosol transmission of infection and control of ventilation in healthcare premises. J Hosp Infect 64(2):100-114

7. Khan MM, Parab SR. simple economical solution for personal protection equipment (face mask/shield) for health care staff during COVID 19. Indian J Otolaryngol Head Neck Surg https://doi.org/10.1007/s12070-020-01863-4

8. Khan MM, Parab SR. Safety guidelines for sterility of face shields during COVID 19 pandemic. Indian J Otolaryngol Head Neck Surg. https://doi.org/10.1007/s12070-020-01865-2

9. Wang D, Hu B, Hu C et al (2020) Clinical characteristics of 138 hospitalized patients with 2019 novel coronavirus-infected pneumonia in Wuhan, China. JAMA. https://doi.org/10.1001/jama. 2020.1585

Publisher's Note Springer Nature remains neutral with regard to jurisdictional claims in published maps and institutional affiliations. 